Profesor Dr. Teodoro Ribera Neumann* y

LL.M. Marcelo Villagrán Abarzúa **

\title{
60 años de la Constitución de la República Federal de Alemania. Algunas referencias de su influencia en Chile
}

* Doctor Iuris Utriusque por la Universidad Julius Maximilian de Würzburg (República Federal de Alemania).

Profesor de la Universidad Autónoma de Chile y de la Universidad de Chile.

** Magister Iuris

Marburgensis LL.M.

Candidato a Doctor iuris utriusque por la Philipps-Universität de Marburg,

Alemania. Profesor de la Universidad Autónoma de Chile.

\section{Introducción}

Con motivo de celebrarse el $60^{\circ}$ aniversario de la Ley Fundamental de la República Federal de Alemania de 1949, nos hemos propuesto analizar su influencia en Chile, considerando que la misma se ha consagrado como una Constitución con un fuerte ascendiente sobre otros sistemas jurídicos.

En el impresionante proceso de reconstrucción vivido por Alemania tras una época de guerras, su Ley Fundamental ha desempeñado un rol cardinal, al asegurar estabilidad jurídica y política. En consideración a lo anterior, muchos Estados han considerado sus normas al momento de modificar o elaborar sus propias Constituciones. Esta situación es un reconocimiento al trabajo serio y metódico realizado por el constituyente alemán, robustecido diariamente por el importante aporte doctrinario y por la trascendental jurisprudencia emanada de su Tribunal Constitucional Federal.

Las Constituciones se han transformado con los años en el basamento de la democracia, por lo que no resulta extraña la aplicación de modelos jurídicos foráneos en la elaboración y mejoramiento de los sistemas normativos internos, siendo para ello requisito necesario, sin embargo, su adaptación a la realidad cultural de cada país, así como reconocer que cada constitución posee sus propios principios fundantes y, consecuentemente, su propio ethos.

Ha sido así, como distintas instituciones jurídicas han cruzado las fronteras con resultados bastante auspiciosos. En algunos casos no se trata de grandes lineamientos, sino que situaciones bastante prácticas y que pueden llegar a tener relación con la organización del Estado, tales como el voto constructivo de no confianza, la existencia del contenido esencial de los derechos, la exigencia de que los partidos políticos practiquen también internamente la democracia, etc. 


\section{Contexto histórico}

El 24 de mayo de 1949 entró en vigencia la Ley Fundamental de la República Federal de Alemania, tras un proceso de estudio y discusión que esperaba superar las profundas heridas dejadas en el pueblo alemán por las dos guerras mundiales y las atrocidades cometidas, en nombre de la nación, por el régimen nacionalsocialista. La reconstrucción del Estado alemán no fue simple y estuvo bajo la estricta supervigilancia de las potencias aliadas que ocupaban el país, los que tenían como objetivo estratégico desmontar la industria bélica, desmilitarizar y desnazificar la sociedad alemana y democratizar la estructura de gobierno.

La Ley Fundamental mencionada constituyó, inicialmente, un orden institucional transitorio para un pueblo que buscaba una reinserción internacional, procurando mediante una nueva regulación, recoger las dolorosas experiencias del pasado de menosprecio a los derechos fundamentales y de utilización de las propias estructuras democráticas para instaurar un sistema totalitario. Se reorganizaba así, asumiendo el compromiso de dirigir sus propios intereses con responsabilidad, evitando que los graves acontecimientos del pasado volvieran a repetirse.

El nuevo orden mundial demandaba una Constitución moderna, capaz de garantizar los derechos esenciales de las personas y de organizar política y administrativamente el Estado. La reconstrucción y las reformas económicas que se iniciaban en el país exigían, además, reglas claras que favorecieran la estabilidad y el desarrollo. Consiguientemente, existió en el constituyente una clara definición a favor de la libertad y la autonomía individual, sobre las cuales se cimentaría la fortaleza del Estado.

El 8 de mayo de 1949, cuatro años después de firmarse la capitulación de Alemania que puso fin al régimen nacionalsocialista, el Parlamento alemán, constituido en las zonas de ocupación de las potencias occidentales, aprobó la nueva Constitución. La Ley Fundamental alemana es, de esta manera, una respuesta al Estado totalitario creado por Hitler, por lo cual se establecieron como cimientos de la nueva Constitución el federalismo y la autonomía municipal, pilares primordiales sobre los que se apoya el sentimiento democrático de Alemania.

La República Federal de Alemania se organizó como una democracia parlamentaria, en la que existe un reconocimiento y especial protección a los derechos fundamentales, entregando notoria importancia al Tribunal Constitucional Federal, como órgano garante del pleno respeto del ordenamiento jurídico. De esta forma, marcados por la experiencia del totalitarismo, la nueva Constitución convierte al Estado en protector de los derechos de los ciudadanos.

En este trabajo nos concentraremos exclusivamente en la influencia que ha tenido la Constitución de la República Federal de Alemania de 1949 en España como al igual en Chile. 


\section{Influencia de la Ley Fundamental en España}

\section{Aspectos generales}

Dado que la Ley Fundamental es del ańo 1949 y la derrota militar alemana estuvo acompañada por un profundo desprestigio moral de sus instituciones, su influencia en las primeras constituciones de posguerra no pudo expresarse, sea porque surgieron ordenamientos constitucionales con anterioridad o bien porque las heridas derivadas de la confrontación bélica hacían impensable considerar como válido un ordenamiento constitucional alemán, surgido durante la ocupación de las potencias vencedoras y destinado a regular una transición, hasta una posterior reunificación.

Con el tiempo, sin embargo, la Ley Fundamental alemana y la capacidad analítica de su doctrina y jurisprudencia fueron permeando, primero, la doctrina y la jurisprudencia de algunos países europeos, para finalmente influenciar las Constituciones de Grecia, España y Portugal, de 1975, 1976 y 1978, respectivamente. ${ }^{1}$ Importante fue, en esta etapa, la cuantiosa literatura traducida y elaborada por especialistas del derecho constitucional y los estudios realizados por destacados profesores de estos países en Alemania, algunos de los cuales incluso se habilitaron para dictar cátedras en universidades alemanas. No hablamos en la especie de una copia de la Constitución, sino que de una adaptación del derecho a las exigencias culturales de cada comunidad. En este sentido, los mayores acercamientos a las normas alemanas se relacionan con la conformación de la judicatura constitucional, las normas de control de legalidad y la dogmática sobre los derechos fundamentales.

\section{Influencias del Derecho Constitucional alemán en España}

La Constitución de Bonn de 1949 influyó significativamente en la conformación del texto de la Constitución española de 1978, por lo que hasta nuestros días la doctrina y jurisprudencia alemana tienen en este país una presencia especial. Tanto las universidades como los tribunales demuestran bastante interés por las decisiones del Tribunal Constitucional Federal y se mantienen muy atentos a la evolución que demuestre en estas materias el derecho alemán, por lo que se habla incluso de una "germanización del derecho español'. ${ }^{2}$ Nos encontramos, por tanto, ante un influjo directo en el contenido

De igual forma se detecta una gran influencia del derecho alemán en otros Estados europeos, ya no a través de sus propias constituciones, sino que por intermedio de la Constitución de Weimar de 1919 y la jurisprudencia y doctrina alemana de posguerra.

2 Cruz Villalón, Pedro: Bericht Spanien, en: Das Grundgesetz im internationalen Wirkungszusammenhang der Verfassungen. 40 Jahre Grundgesetz, Ulrich Battis, Ernst Gottfried Mahrenholz und Dimitris Tsatsos (Editores), Schriften zum Öffentlichen Recht, Band 588, Editorial Duncker \& Humblot, Berlin, Alemania, 1990, pp. $93-$ 108, p. 93. 
de la Constitución española de 1978, pero también en la interpretación de sus normas, para lo cual se intenta seguir los mismos criterios que en Alemania.

La transición democrática española significó un cambio drástico en sus instituciones, debiendo garantizarse en la Constitución una serie de derechos que en diversos lugares del mundo ya existían con bastante anterioridad. De esta forma llegaron abundantes conceptos nuevos a la institucionalidad del país, como la primacía constitucional, los derechos fundamentales realmente garantizados, un ordenado parlamentarismo y un debido equilibrio entre el reconocimiento de las autonomías locales con la consagración de un sólido gobierno central. Cabe recordar al respecto, que la Constitución española de 1931 ya había recibido influencias de la Constitución alemana de 1919 en materias de orden social, sobre la posición jurídica del Presidente de la República y el régimen democrático. ${ }^{3}$

Un claro ejemplo de este ascendiente lo configura el artículo 1, inciso primero, de la Constitución española que señala: "España se constituye en un Estado social y democrático de Derecho...", norma que reproduce lo dispuesto por el artículo 20 inciso primero de la Ley Fundamental alemana con igual significado, pero distinto efecto, debido a que la de España, en cuanto a los principios rectores de la política social y económica, se abstiene expresamente de realizar pagos por concepto de derechos sociales. De igual modo se redacta la opción por entregar a una organización o institución internacional el ejercicio de competencias derivadas de la Constitución o el principio de legalidad. Una influencia importante se produce también en el capítulo de los derechos y deberes fundamentales, de los que adopta incluso su nombre. No es de extrańar que el artículo 10 , que comienza a tratar esta materia, se refiera a la dignidad de la persona, tal como lo hace la Ley Fundamental de Alemania.

Considerando lo anterior, es recurrente que ante una problemática jurídica en España se busque como fuente interpretativa la jurisprudencia y doctrina que exista sobre el particular en Alemania. Lo anterior ocurrió, por ejemplo, con la teoría de la dogmática de los derechos fundamentales, de origen alemán, que los dividió en derechos individuales o subjetivos de defensa frente al Estado y en elementos de un orden institucional o deberes positivos por parte del propio Estado.

Es igualmente destacable que en la esfera de las garantías individuales, consagrada en España gracias a la influencia la Constitución de Alemania de 1949, se contemple expresamente el respeto de los derechos en su esencia (Wesensgehaltsgarantie) y la garantía institucional. La protección del contenido esencial de los derechos fundamentales, que busca preservar el valor que se encuentra en cada uno de ellos, presenta una influencia clara del artículo 19 inciso segundo de la Constitución de Bonn de 1949. Si bien su redacción no es tan exigente como la alemana, que señala que "en ningún caso un derecho fundamental podrá ser afectado en su contenido esencial”, se busca al igual que en ella establecer una limitación absoluta a la actuación del legislador en

Ibidem, p. 94. 
la regulación del ejercicio de tales derechos y libertades. La Constitución de Alemania de 1949 lo formula como una prohibición y la de España como un mandato, pero el efecto de ambas es el mismo.

Por su parte la garantía institucional, que al igual que la Wesensgehaltsgarantie tiene su origen en la Constitución de Weimar de 1919, se refiere a la protección constitucional de una organización o institución. No responden al esquema del derecho objetivo, sino que tratan de asegurar la existencia de una institución, a fin de que el legislador reconozca esa existencia y no intente por medio de su actuación desconocerla. Por no reconocerse en esta garantía los derechos subjetivos, no se encuentran protegidos por el límite del contenido esencial. El legislador goza así de una gran libertad para configurar su contenido, incurriendo sólo en inconstitucionalidad cuando afecta por completo la institución. ${ }^{4}$ Tanto la garantía institucional como el límite de los derechos en su esencia buscan asegurar la primacía de la Constitución sobre la acción del legislador y establecen límites a su actuación, que no podrá propasar.

A pesar de las diferencias existentes entre ambos sistemas políticos, la Ley Fundamental alemana de 1949 ha influido decididamente en el modelo democrático adoptado por España, una estricta democracia representativa, en la que no existen elementos de democracia directa. Un claro ejemplo de esta influencia lo encontramos en las normas que se refieren a los partidos políticos, que son muy semejantes (el artículo 6 de la Constitución española de 1978 y el artículo 21 inciso primero de la Constitución de Bonn de 1949). Del mismo modo, la moción de censura constructiva (Mißtrauensvotums) presente en la Ley Fundamental de Alemania influye notoriamente en la censura política española. Igual situación ocurre con la cuestión de confianza y la posibilidad de disolver el parlamento. ${ }^{5}$

Destacable es también la semejanza que se percibe en las normas que garantizan la igualdad de trato en todos los lugares del territorio y la creación de un Fondo de Compensación con destino a gastos de inversión, como lo establece respectivamente la Ley Fundamental de Alemania en sus artículos 33 inciso 1 y 104 a) inciso cuarto, como los referentes a la garantía de la autonomía municipal y la regulación del gobierno central con las autonomías regionales y municipales.

La Constitución como la jurisprudencia y doctrina española serían completamente diversas sin la influencia de la Ley Fundamental de Alemania y el pensamiento jurídico alemán. Este factor no nos puede resultar lejano, por ser Espańa un modelo para ciertos académicos y el origen de abundante literatura para toda Hispanoamérica, con lo cual indirectamente la influencia del derecho alemán extiende su campo de acción gracias a la doctrina y jurisprudencia espańola hacia el continente americano.

4 Baño León, José María: La distinción entre derecho fundamental y garantía institucional en la Constitución Espańola, Revista Española de Derecho Constitucional, Centro de Estudios Políticos y Constitucionales, Año 8, № 24, Madrid, España, Septiembre-Diciembre 1988, pp. 155-179, p. 157.

Cruz Villalón, op. cit., p. 102 y s. 


\section{Influencia de la Ley Fundamental alemana en la Constitución chilena}

\section{Relaciones jurídicas chileno-alemanas}

Si bien el idioma alemán ha sido en muchas ocasiones una barrera difícil de vencer, nuestro medio local se ha nutrido de la experiencia jurídica alemana a través de dos medios. Por un lado, la influencia directa ha provenido a través de la colaboración universitaria y del intercambio docente entre Chile y Alemania aprovechando, de esta manera, los conocimientos jurídicos de chilenos que han estudiado en el mundo alemán, pero igualmente ha existido una influencia indirecta por los escritos de importantes profesores espańoles que han realizado idéntico cometido o por intermedio de chilenos que han cursado estudios en universidades españolas. Sin lugar a dudas, la estrecha relación existente entre universidades alemanas y españolas, las que envían a sus alumnos destacados a realizar sus doctorados e incluso a habilitarse de profesores a Alemania, ha facilitado el compenetrarse del derecho alemán.

En los últimos lustros, y a consecuencia de las acciones impulsadas por las fundaciones políticas alemanas, se ha incrementado la presencia de estudiantes chilenos en Alemania para estudiar derecho o ciencias políticas. ${ }^{6}$ Tal es el caso, entre otros, de Roberto Mayorga; Mario Fernández; Ricardo Hormazábal; Carlos Huneeus; Roberto Cifuentes; Otto Boye; Guillermo Laurent; Pedro Medrano; Edgardo Riveros y Claudio Troncoso, becados por la Fundación Konrad Adenauer; y Enrique Barros, Antonio Bascuñán, Felipe Guevara, Juan Carlos Johow, Claudio Osorio, Jaime Reyes, Teodoro Ribera, Marta Salazar Jorge Sandrock, José Ignacio Vásquez, becados por la Fundación Hanns Seidel. En una gran mayoría, estos ex becados han contribuido a transferir al medio local las experiencias y conocimientos jurídicos adquiridos en Alemania, tanto en las Universidades chilenas o en los cargos públicos que han ocupado. ${ }^{7}$

\section{Relaciones jurídicas alemanas con Chile}

En medios académicos de lengua alemana ha existido un creciente interés por los acontecimientos políticos y jurídicos chilenos. No deja de sorprender que uno de los

\footnotetext{
En esta materia se destaca la labor desarrollada por la Fundación Konrad Adenauer, vinculada al Partido Democratacristiano alemán y la Fundación Hanns Seidel, relacionada con la Unión Socialcristiana de Baviera.

A manera de ejemplo puede indicarse que Roberto Mayorga presidió el Comité de Inversiones Extranjeras; Mario Fernández, ex Ministro de Estado y actual Ministro del Tribunal Constitucional; Carlos Huneeus fue Embajador de Chile en Bonn, siendo reemplazado por Roberto Cifuentes, siendo actualmente profesor de la Universidad de Chile; Otto Boye fue Embajador en Venezuela; Claudio Troncoso es actualmente Director Jurídico del Ministerio de Relaciones Exteriores; Pedro Medrano fue Embajador ante la FAO. Enrique Barros es profesor en la Universidad de Chile y colabora en el Centro de Estudios Públicos; Marta Salazar ha publicado diversos artículos jurídicos; Felipe Guevara es actual Alcalde de Lo Barnechea; Claudio Osorio, Antonio Bascuñan, Cristián Johow, Jorge Sandrock son profesores de la Universidad Adolfo Ibáńez; José Ignacio Vásquez es profesor en la Universidad de Chile y Jaime Reyes profesor investigador en la Universidad Diego Portales.
} 
juristas más importantes del mundo alemán, Hans Kelsen, se sintiera en su juventud atraído por la Constitución chilena de 1925 y escribiera, un año después de su promulgación, un breve ensayo en la Revista de Derecho Público, comentando una traducción efectuada por Martín Figueroa ${ }^{8}$. Kelsen, siendo ya profesor en la Universidad de Viena, señalaba que "la nueva Constitución chilena es un producto de aquel movimiento antiparlamentario, que también hoy es posible captar en Europa por doquier". Culminaba su comentario reconociendo que la Constitución de 1925 era una carta fundamental "trabajada técnicamente en forma limpia".

Revisando la literatura especializada alemana relativa al Derecho Público, nos encontramos en el año 1967 con el trabajo del profesor chileno, de la Universidad de Concepción, Wolfgang Prieur Koelling y su estudio sobre "El Desarrollo del Derecho Constitucional en Chile", el cual actualizaría luego en el año $1971^{10}$.

Serían, sin embargo, los acontecimientos políticos de los años 1970 a 1980 los que más atracción despertaron en medios jurídicos y políticos alemanes. Así es como se realizaron diversas publicaciones en pro y contra de los sucesos en torno a esos ańos ${ }^{11}$.

Un hecho significativo en el traspaso de experiencias constitucionales alemanas a Chile fue el resultado de la visita del entonces Ministro Presidente del Estado Libre de Baviera Franz Joseph Strauss a Chile en el año 1976, para conmemorar los 125 años de la llegada de los primeros colonizadores alemanes al sur. Producto de esta visita, se inició un largo trabajo de la Fundación Hanns Seidel, la que organizó seminarios en Chile $^{12}$ y en Alemania ${ }^{13}$ para traspasar conocimientos sobre temas constitucionales. Por otro lado, la presencia en Chile del Dr. Gerhard Wolfgang Goldberg, quien había tenido que huir de Alemania por motivos raciales y había hecho de Chile su segunda patria, generó un fluido intercambio académico entre la Pontificia Universidad Católica de Chile y la Universidad Julius Maximilian de Würzburg. Debemos destacar en este intercambio la visita a Chile del asesor de la Cancillería bávara en materias constitucionales e internacionales, el profesor Dr. Dieter Blumenwitz, quien no sólo dio conferencias en la Universidad Católica y en la Universidad de Chile ${ }^{14}$, sino que se

8 Figueroa, Martin, Die neue Staatsverfassung von Chile, Zeitschrift für Öffentliches Recht, Band V, 1926, p. 596 y ss.

9. Kelsen, Hans, Bemerkungen zur chilenischen Verfassung, p. 616 y 619.

10 Prieur Koelling, Wolfgang, Die Entwicklung des Verfassungsrechts in Chile, Jahrbuch des öffentlichen Rechts, 1967,p.411 y ss.

11 Valga como ejemplo el trabajo de Wolfgang Prieur, Die Entwicklung des Verfassungsrechts in Chile, Jahrhuch des öffentlichen Rechts, 1971, p. 535 y ss; Dieter Nohlen, Sozio-Ökonomischer Wandel und Verfassungsreform in Chile 1925-1972, Verfassung und Recht in Übersee, 1973, p. 65 y ss; Dieter Nohlen, Das Sozialistisclie Experiment, Hamburgo, 1973; Dieter Blumenwitz, Die neue Verfassung der Republik Chile, Jahrbuch des öfentlichen Rechts, 1981, p. 617 y ss.

12 Estos seminarios se realizaron en colaboración con la Universidad Católica de Chile y la Universidad de Chile, como también con el Centro de Estudios Públicos.

13 En el ańo 1978 se organizó en Munich un seminario sobre Chile, participando invitados chilenos y alemanes. Sus conclusiones y ponencias fueron publicadas en: Hanns Seidel Stiftung, Politische Studien, Chile, ein schwieriger Weg, Sonderheft 1, 1978, Munich, 1978.

14 Véase al respecto: Bulnes, Luz, Comentario a la Conferencia del Dr. D. Blumenwitz sobre Instituciones Políticas, en: Departamento de Derecho Público, Facultad de Derecho de la Universidad de Chile, Boletín de Derecho 
entrevistó con miembros del gobierno y se reunió con los integrantes de la Comisión de Estudio de la Nueva Constitución Política de la República.

Sea por estos contactos o bien por la relevancia que había alcanzado la Ley Fundamental alemana, durante diversas sesiones de la Comisión de Estudio se citó la Constitución alemana de 1949 o se hizo referencia a sus disposiciones, plasmándose alguna de sus ideas en la actual Constitución chilena. Es más, ya al iniciar el trabajo dicha Comisión, el 24 de septiembre de 1973, se acordó solicitar, entre otros textos constitucionales, la Ley Fundamental de la República Federal de Alemania. ${ }^{15}$

En este trabajo analizaremos los casos mas preclaros de la recepción de instituciones alemanas en Chile, que visualizamos en las normas sobre la exigencia de que los partidos políticos practiquen la democracia interna, la defensa de la democracia, la garantía constitucional que ningún derecho puede ser afectado en su contenido esencial y la conformación del Tribunal Constitucional.

\section{La democracia interna de los partidos políticos}

Los partidos políticos asumieron en Chile durante el período 1925-1973 un creciente monopolio en la representación ciudadana, sin que se regulara en norma alguna los mecanismos necesarios para garantizar una mínima estructura democrática. ${ }^{16}$

En el Pacto de Garantías Constitucionales de 1970, que tuvo por efecto afianzar a nivel constitucional el sistema democrático ante la ascensión al poder de los Partidos de la Unidad Popular, se estableció una profunda regulación en favor de los partidos políticos en el artículo $9^{\circ}$ de la Constitución, el cual indicaba: "Los partidos políticos gozarán de libertad para darse la organización interna que estimen conveniente...".

Los constituyentes de 1970, buscaron con esta disposición constitucional garantizar y defender la existencia de los partidos políticos frente a un posible atentado dirigido desde la esfera estatal. Si bien este objetivo fue plenamente logrado, instituyeron en la práctica diversos derechos y facultades de los partidos políticos para intervenir en los asuntos públicos, sin que ello llevara como contrapartida normativas para garantizar su democracia interna o para impedir que asumieran una representación monopólica frente a otras expresiones populares ${ }^{17}$.

Público, Santiago, abril de 1979.

15 De esta forma, varias de sus disposiciones sirvieron como inspiración en materia de las libertades de expresión, de enseñanza y de culto, de los derechos de reunión y de propiedad, y por sobre todo, en cuanto a la esencia de los derechos.

16 Al respecto puede consultarse Ribera Neumann, Teodoro, Estatuto Jurídico de los partidos políticos en Chile. Veinte años de la Ley Orgánica Constitucional de los partidos políticos, en: Arturo Fontaine, Cristián Larroulet, Jorge Navarrete e Ignacio Walker (editores), La Reforma de los Partidos Políticos en Chile, Editorial Tipográfica, Santiago, 2008, pág. 127 y ss.

17 Ribera, Teodoro, Democracia Interna y Financiamiento de los Partidos Políticos, en: Centro de Estudios Públicos, Documentos de Trabajo No 12, enero 1989. 
La Comisión de Estudio, encargada de redactar la que sería la Constitución de 1980, estimó indispensable incorporar en el texto constitucional el Estatuto de los Partidos Políticos, precisando las bases y la organización que debían observar para constituirse democráticamente y participar sólo en aquellas actividades que le son inherentes a sus fines propios ${ }^{18}$.

De esta manera, la Constitución de 1980 modificó sustancialmente la postura de los partidos políticos ante la sociedad y del Estado y consagró una extensa regulación de los mismos y de la actividad política ${ }^{19}$, disponiendo además que "las fuentes de su financiamiento no podrán provenir de dineros, bienes, donaciones, aportes ni créditos de origen extranjero; sus estatutos deberán contemplar normas que aseguren una efectiva democracia interna." Tanto la norma sobre la transparencia de los recursos partidistas como la relativa a su estructura democrática interna se inspiraron en el artículo 21 (1) de la Ley Fundamental alemana, el cual alude igualmente a ello al indicar: "Los partidos participan en la formación de la voluntad politica del pueblo. Su fundación es libre. Su organización interna debe responder a los principios democráticos. Los partidos deberán dar cuenta públicamente de la procedencia y uso de sus recursos, así como de su patrimonio."

En lo relativo a la democracia interna, parece lógico y elemental que, deseando los partidos influir en el ámbito político de la sociedad democrática y acceder al poder, también deban subordinarse a los mismos principios democráticos. Esta circunstancia, sin embargo, no constituyó una situación lógica en Chile, donde los partidos se caracterizaron por ser organizaciones oligárquicas o caudillistas. Con la norma constitucional actual, imbuida del derecho constitucional alemán, que busca evitar los partidos totalitarios en cuanto a su estructura, se ha avanzado significativamente en la aceptación de la democracia interna en los partidos, sin perjuicio de lo cual cabe reconocer que el ideal constitucional dista aun de ser una realidad plena.

El Tribunal Constitucional Federal, comentando esta norma, indicó que esto implicaba que "su estructura debe estar montada desde abajo hacia arriba, teniendo los militantes el derecho a participar en la toma de decisiones" ${ }^{20}$. Por su parte, el Tribunal Constitucional chileno ha determinado que la ley orgánica constitucional que regula a los partidos políticos debe respetar la libertad de los afiliados de darse la organización interna que acuerden, respetando, eso si, la democracia interna, por lo que dicho cuerpo legal debe contemplar un marco normativo general, pero sin entrar a regular de manera pormenorizada el tema. ${ }^{21}$

18 Comisión de Estudio de la Nueva Constitución Política de la República, Actas Oficiales, Talleres Gráficos de Gendarmería, Santiago, 1975, Sesión 1a, celebrada en lunes 24 de septiembre de 1973, Tomo I, p. 8.

19 Así, los artículos $8^{\circ}$, inciso $2^{\circ}$ (hoy derogado), $19^{\circ} \mathrm{N}^{\circ} 11$, inciso $3^{\circ} ; 10^{\circ} \mathrm{N}^{\circ} 19$, inciso $3^{\circ} ; 23^{\circ} ; 84^{\circ}$, inciso $3^{\circ}$, como la disposición décima transitoria.

20 Stein, Eckhard, Derecho Político, Editorial Aguilar, Madrid, 1973, p. 162.

${ }^{21}$ Sentencia del Tribunal Constitucional Rol N. ${ }^{\circ} 43$, Considerando 47 y ss., a citarse a futuro como STC 43/47. 


\section{La defensa de la democracia}

La Constitución de 1980 abandonó el concepto neutro de democracia como un mero sistema técnico de distribución del poder, y asumió como propia la concepción según la cual, la democracia implica también la subsistencia, más alta de las mayorías y minorías, de ciertos derechos fundamentales que garantizan la dignidad de las personas y la convivencia democrática.

Derivado del concepto valórico de democracia, la Constitución incorporó en el artículo $8^{\circ}$ (texto original) una extensa disposición que tenía por objeto restringir el uso de ciertos derechos fundamentales de quienes buscaban la sustitución o eliminación del sistema democrático, considerando dichas acciones, sea que fueren realizadas por individuos o agrupaciones políticas, como un uso abusivo de las garantías constitucionales.

Esta disposición se inspiró en los artículos $18^{\circ}$ y $21^{\circ}$, inciso segundo, de la Ley Fundamental alemana, mediante los cuales el constituyente alemán defiende el orden básico de libertad y democracia frente al uso abusivo de ciertos derechos fundamentales y busca impedir el resurgimiento de agrupaciones políticas totalitarias, luego de las desastrosas consecuencias del gobierno nacionalsocialista y de la experiencia comunista en Europa Central y del Este. ${ }^{22}$

El artículo $8^{\circ}$ luego fue derogado en el año 1989, fruto de una negociación entre diversos partidos políticos y el gobierno militar ${ }^{23}$, trasladándose su contenido, con una redacción distinta y más acotada, al artículo $19^{\circ} \mathrm{N}^{\circ} 15$, incisos $6^{\circ}$ al $8^{\circ}$, de la Constitución. ${ }^{24}$

Cabe tener presente que los artículos $18^{\circ}$ y $21^{\circ}$ inciso $2^{\circ}$ de la Ley Fundamental alemana han servido como un elemento referencial para destacar las connotaciones antidemocráticas en la vida política alemana. Además, invocando el artículo $9^{\circ}$ de la Ley Fundamental de Alemania y la normativa legal pertinente, se han declarado ilícitas organizaciones de corte marxista, nacionalsocialista o que promueven el conflicto racial, alcancen o no a reunir las características de un partido político.

22 Comisión de Estudio, op. cit., Sesión 1, Tomo I, p. 5; Sesión 10, Tomo I, p. 10, y Sesión 24, Tomo I, p. 387. Al redactarse por esta Comisión el texto denominado "Metas Fundamentales para la Nueva Constitución" se indicaba en el literal B) del número 2 que: "debe contemplarse un precepto que declare que los partidos políticos que por sus fines o la conducta de sus partidarios vayan en contra del sistema democrático de gobierno, son contrarios a la Constitución. Disposiciones análogas se contemplan en las Constituciones más modernas de países que han atravesado por estas emergencias; baste citar como ejemplo, la Constitución alemana”. Comisión de Estudio, ob. cit., Sesión 3, p. 2.

23 Consúltese al respecto Andrade Geywitz, Carlos, Reforma de la Constitución Política de la República de Chile de 1980, Editorial Jurídica de Chile, Santiago, 1991, pág. 202 y ss.

24 En particular, el inciso $6^{\circ}$ describe la conducta ilícita e indica: "La Constitución garantiza el pluralismo político. Son inconstitucionales los partidos, movimientos, u otras formas de organización cuyos objetivos, actos o conductas no respeten los principios básicos del régimen democrático y constitucional, procuren el establecimiento de un sistema totalitario, como asimismo aquellos que hagan uso de la violencia, la propugnen o inciten a ella como método de acción política. Corresponderá al Tribunal Constitucional declarar esta inconstitucionalidad." 


\section{La garantía del contenido esencial de los derechos}

Una de las innovaciones más esenciales de la Constitución chilena de 1980 lo constituye todo un andamiaje de derechos fundamentales destinados a aumentar los ámbitos de libertad del individuo frente al Estado, al igual que diversas normas que limitan el accionar estatal.

Dado que en la vida social los derechos de las personas colisionan entre sí o con las normas administrativas o legales que emanan de la autoridad, el legislador adopta regulaciones o establece limitaciones a ciertos derechos y libertades para darle a otros una mayor preeminencia. En la práctica, es de fundamental importancia evitar que a través de regulaciones o limitaciones los derechos y libertades reconocidos por la Constitución no queden en una simple declaración, sino que, en todo caso y ante todo evento, los mismos sean efectivamente resguardados y protegidos.

Para impedir que en función de privilegiar ciertos derechos y libertades se pueda conculcar la existencia de otros derechos y libertades, también reconocidos y garantizados por la Constitución, es que la Carta Magna chilena incorporó en el artículo $19^{\circ} \mathrm{N} .{ }^{\circ} 26$ la idea de que los derechos fundamentales tienen un núcleo o contenido esencial que el legislador no puede afectar, inspirándose en la Ley Fundamental alemana. Dicha disposición indica que la Constitución asegura a todas las personas "la seguridad que los preceptos legales que por mandato de la Constitución regulen o complementen las garantías que ésta establece o que las limiten en los casos en que ella lo autoriza, no podrán afectar los derechos en su esencia, ni imponer condiciones, tributos o requisitos que impidan su libre ejercicio."

En la sesión N ${ }^{\circ} 150$ de la Comisión de Estudio, el Presidente de la Subcomisión de Derecho de Propiedad, don José María Eyzaguirre, indicó que "bubo consenso en la Subcomisión en el sentido de tomar la idea de la Constitución alemana" 25 . Dicha proposición habría provenido, según Enrique Ortúzar, de don Julio Philippi, "siguiendo el criterio de la Constitución de la República Federal de Alemania"26. De ahí entonces, que diversos seńores comisionados citaron reiteradamente la Ley Fundamental alemana para sostener la conveniencia de introducir una norma que protegiese la esencia de todos los derechos, y no de algunos en particular, "tal como lo hace la Constitución alemana en su artículo $19^{\circ} .^{27}$

Comisión de Estudio, ob. cit., p. 18.

Comisión de Estudio, ob. cit., Sesión 155, p. 15

La Ley Fundamental no proporciona mayores indicios sobre lo que debe entenderse por "contenido esencial" (Wesensgehalt). El Tribunal Constitucional Federal alemán ha precisado que el "contenido esencial" de un derecho debe determinarse considerando su importancia en el contexto general de los derechos fundamentales (BVerfGE. 22,219), siendo el mismo intocable, no pudiendo relativizarse sobre la base del criterio de la proporcionalidad entre el medio y el fin, pues se trataría en este caso de un límite final absoluto (BVerfGE. 16,201). No procede, de esta manera, privilegiar otro derecho individual o una potestad de una autoridad pública, si se viola como contrapartida la esencia de un derecho fundamental. Un completo análisis relativo al contenido esencial en la Constitución Alemana se puede encontrar en: Juan Carlos Gavara de Cara, Derechos Fundamentales y Desarrollo Legislativo, La Garantía del Contenido esencial de los Derechos Fundamentales en la Ley Fundamental de Bonn, Centro de Estudios Constitucionales, Madrid, 1994. 
La norma alemana que inspiró el precepto constitucional chileno fue el artículo $19^{\circ}$ inciso $2^{\circ}$ de la Ley Fundamental, que indica que: "en ningún caso puede un derecho fundamental ser afectado en su contenido esencial'.

La Constitución chilena acogió la idea alemana del contenido esencial de los derechos, pero en una forma más amplia, pues no sólo garantiza su esencia, sino que igualmente prohíbe que se impongan condiciones, tributos o requisitos que impidan su libre ejercicio. Esta diferencia conlleva que al constituyente no le basta con que se resguarde el atributo propio de un derecho, sino que ordena al legislador a que con su actividad regulatoria brinde la mayor libertad posible en su ejercicio.

La Constitución chilena distingue en el artículo 19, N. 26 entre el núcleo irreductible e inafectable, que es la esencia misma del derecho ("no podrá afectar los derechos en su esencia"), y el libre ejercicio de dicho derecho, que es un límite flexible y que debe expandirse al máximo de acuerdo al principio favor libertatis, en la medida que no afecte los derechos de terceros ni el bien común. Mientras que la esencia de un derecho es un límite absoluto, el límite de expansión derivado del libre ejercicio de los derechos puede ser objeto de restricciones o limitaciones con el fin de resguardar otros derechos de igual o superior jerarquía, respetando las exigencias constitucionales.

El Tribunal Constitucional chileno ha entendido que "un derecho es afectado en su "esencia" cuando se le priva de aquello que le es consustancial de manera tal que deja de ser reconocible." ${ }^{28}$ Esta definición sólo aclara o precisa un concepto abstracto, pero será materia jurisprudencial, en cada caso, determinar si un derecho es o no violado en su esencia.

El mismo Tribunal Constitucional ha indicado que se "impide el libre ejercicio en aquellos casos en que el legislador lo somete a exigencias que lo hacen irrealizable, lo entraban más allá de lo razonable o lo privan de tutela jurídica". ${ }^{29}$ Igualmente ha expresado en forma reiterada que se incurre en una inconstitucionalidad si el legislador entraba un derecho "más de lo razonable" o lo hace en forma "imprudente".

Esta jurisprudencia está fuertemente influenciada por una similar conceptualización que hace el Tribunal Constitucional español, que sobre la materia, interpretando el artículo 53.1 de la Constitución espańola de 1978 que recoge la idea del "contenido esencial”, sentenció lo siguiente:

"De este modo, se rebasa o desconoce el contenido esencial cuando el derecho queda sometido a limitaciones que lo hacen impracticable, lo dificultan más allá de lo razonable o lo despojan de la necesaria protección." 30 


\section{La función del Tribunal Constitucional}

La instauración de un Tribunal Constitucional en Chile, como supremo guardián de la Constitución, estuvo indudablemente influenciada por el destacado rol que ha desempeñado el Tribunal Constitucional Federal en Alemania. Cabe recordar, que el Tribunal Constitucional consagrado en la Constitución de 1980 tiene sus orígenes más inmediatos en la reforma constitucional de 1970, que dio nacimiento a esta institución, durante cuya tramitación se tuvo presente, entre otras constituciones políticas, a la Ley Fundamental alemana. ${ }^{31}$

Por su parte, al analizarse la conformación de este órgano jurisdiccional en la Comisión de Estudio, las referencias al Tribunal Constitucional Federal alemán fueron frecuentes. Así se hizo al analizarse la conformación del Tribunal en lo que respecta la duración en el cargo de sus integrantes ${ }^{32} \mathrm{y}$ en el nombramiento de jueces por órganos públicos ${ }^{33}$, como al igual respecto de sus atribuciones, donde se hizo referencia a las diversas vías existentes en Alemania para obtener la declaración de inconstitucionalidad de una ley, en especial el control concreto y abstracto de constitucionalidad ${ }^{34}$ como para resolver los atentados contra el orden institucional. ${ }^{35}$

\section{Conclusiones}

El presente trabajo ha buscado resaltar en el año de su $60^{\circ}$ aniversario la relevancia de la Constitución de la República Federal de Alemania de 1949 y su influencia en Chile. El reconocimiento y consagración que hace la Constitución alemana de los derechos fundamentales, del sistema democrático, del respeto y garantía de las autonomías y el establecimiento de un Tribunal Constitucional capaz de hacer respetar su texto, son sólo muestras del gran contenido de esta Ley Fundamental y del motivo que han tenido otras naciones en imitar su normativa. Junto a ello, la tarea del Tribunal Constitucional Federal alemán y de la doctrina alemana en el análisis e interpretación de sus disposiciones han contribuido a una mejor aplicación del derecho para beneficio de la convivencia humana.

En el caso chileno, la estrecha relación académica entre universidades alemanas y chilenas se ha visto beneficiada por los programas de becarios que han impulsado

31 Alejandro Silva Bascuñan, El Tribunal Constitucional, en: Eduardo Frei, Sergio Molina, Enrique Evans, Gustavo Lagos, Alejandro Silva y Francisco Cumplido, en: Reforma Constitucional 1970, Editorial Jurídica de Chile, Santiago 1970, pág. 213.

32 Al respecto véanse las consideraciones del comisionado Enrique Evans en: Comisión de Estudio de la Nueva Constitución Política de la República, Actas de la Comisión, Talleres Gráficos de Gendarmería, Santiago, 1981, Sesión $314^{\mathrm{a}}$, pág. 738 .

33 Así, el comisionado Raúl Bertelesen en: Comisión de Estudio, Sesión 358a , pág. 767.

34 Cfr. Las expresiones del comisionado Raúl Bertelsen en: Comisión de Estudio, Sesión N. $359^{a}$,pág. 790 y Sesión N. ${ }^{\circ} 397^{a}$, pág. 601.

35 Idem, Sesión N. $344^{a}$, pág. 479. 
las fundaciones políticas alemanas, las que han permitido intensificar el contacto académico y facilitado la conversión y eventual aplicación de dichas visiones a nivel político y jurídico.

Con todo, es necesario tener presente que pretender apropiarse de la doctrina y jurisprudencia alemana en bloque, sin discriminar el ámbito jurídico en que se encuentra inserta, puede conllevar en la práctica un contrabando normativo, carente de legitimación democrática, esto es, una mutación de nuestra estructura sin fundamento normativo.

Por ello, la doctrina y jurisprudencia alemanas son siempre interesantes e ilustradoras para la doctrina nacional, pero deben ser asumidas con cautela por la jurisprudencia. Así, si bien la Ley Fundamental alemana y la Constitución chilena establecen regímenes políticos democráticos, sus sistemas políticos difieren luego el uno del otro. A manera de ejemplo, mientras Alemania define su régimen político como un Estado democrático y social de derecho, en Chile el carácter social del Estado carece de reconocimiento constitucional y en la última gran reforma a la Carta Magna no fue acogido.

Finalmente podemos destacar que la influencia del Derecho Constitucional alemán en la jurisprudencia constitucional chilena es creciente, tal como se constata en su incorporación en algunos fallos del Tribunal Constitucional, los cuales se remiten directamente a la doctrina y jurisprudencia del Tribunal Constitucional Federal alemán, o bien a fuentes accesorias como lo son algunos autores alemanes o españoles. ${ }^{36}$

36 En esta materia puede destacarse las reiteradas citas a la libertad de configuración legislativa que le compete al Parlamento, y en general el respeto de la autonomía de los órganos del Estado, que debe resguardar el órgano jurisdiccional, indicándose que "como lo ha consignado el Tribunal Constitucional alemán, el legislador goza de un espacio de reglamentación, valoración y examen propio que, en principio, no puede ser revisado por los tribunales. Así, STC 1065/ 36; STC 821/16 y STC Rol 796, Voto de minoría, Considerando 3. 